\title{
Estradiol-induced object recognition memory consolidation is dependent on activation of mTOR signaling in the dorsal hippocampus
}

\author{
Ashley M. Fortress, ${ }^{1,8}$ Lu Fan, 2,3,4,8 Patrick T. Orr, ${ }^{2,5}$ Zaorui Zhao, $^{2,6,7}$ \\ and Karyn M. Frick ${ }^{1,2,9}$ \\ ${ }^{1}$ Department of Psychology, University of Wisconsin-Milwaukee, Milwaukee, Wisconsin 53211, USA; ${ }^{2}$ Department of Psychology, \\ Yale University, New Haven, Connecticut 06520, USA
}

\begin{abstract}
The mammalian target of rapamycin (mTOR) signaling pathway is an important regulator of protein synthesis and is essential for various forms of hippocampal memory. Here, we asked whether the enhancement of object recognition memory consolidation produced by dorsal hippocampal infusion of $17 \beta$-estradiol $\left(\mathrm{E}_{2}\right)$ is dependent on mTOR signaling in the dorsal hippocampus, and whether $\mathrm{E}_{2}$-induced $\mathrm{mTOR}$ signaling is dependent on dorsal hippocampal phosphatidylinositol 3-kinase (PI3K) and extracellular signal-regulated kinase (ERK) activation. We first demonstrated that the enhancement of object recognition induced by $\mathrm{E}_{2}$ was blocked by dorsal hippocampal inhibition of ERK, PI3K, or mTOR activation. We then showed that an increase in dorsal hippocampal ERK phosphorylation 5 min after intracerebroventricular (ICV) $E_{2}$ infusion was also blocked by dorsal hippocampal infusion of the three cell signaling inhibitors. Next, we found that ICV infusion of $\mathrm{E}_{2}$ increased phosphorylation of the downstream mTOR targets S6K (Thr-421) and 4E-BPl in the dorsal hippocampus 5 min after infusion, and that this phosphorylation was blocked by dorsal hippocampal infusion of inhibitors of ERK, PI3K, and mTOR. Collectively, these data demonstrate for the first time that activation of the dorsal hippocampal mTOR signaling pathway is necessary for $E_{2}$ to enhance object recognition memory consolidation and that $E_{2}$-induced mTOR activation is dependent on upstream activation of ERK and PI3K signaling.
\end{abstract}

The potent estrogen $17 \beta$-estradiol $\left(\mathrm{E}_{2}\right)$ is a critical regulator of hippocampal synaptic morphology. In rodents and nonhuman primates, $E_{2}$ increases hippocampal levels of synaptic proteins, including the presynaptic proteins synaptophysin and syntaxin, and the postsynaptic proteins spinophilin and PSD-95 (Brake et al. 2001; Frick et al. 2002; Choi et al. 2003; Spencer et al. 2008; Waters et al. 2009). E $_{2}$ also significantly increases hippocampal CA1 dendritic spine density in rodents and nonhuman primates (Woolley and McEwen 1992, 1993; Hao et al. 2003; Frick et al. 2004). Interestingly, an increase in CA1 spine synapse formation in the rodent hippocampus can be observed within 30 min of treatment (MacLusky et al. 2005), suggesting that $E_{2}$ may rapidly regulate protein synthesis. Indeed, in vitro studies have demonstrated that $\mathrm{E}_{2}$ rapidly increases new protein synthesis of the cell signaling molecule $\alpha$-CaMKII and the postsynaptic scaffolding protein PSD-95 (Akama and McEwen 2003; Sarkar et al. 2010). Despite the fact that long-term hippocampal memory consolidation requires new protein synthesis (for review, see Klann and Sweatt 2008), the extent to which protein synthesis is involved in the ability of $\mathrm{E}_{2}$ to enhance hippocampal memory has not yet been tested.

Present addresses: ${ }^{3}$ Department of Pharmacology, Yale University School of Medicine, New Haven, Connecticut 06520, USA; ${ }^{4}$ Department of Neurology, Changhai Hospital, Shanghai 200433, China; ${ }^{5}$ Geisinger Health System, Danville, Pennsylvania 17822, USA; ${ }^{6}$ Department of Anesthesiology and ${ }^{7}$ Center for Shock, Trauma and Anesthesiology Research (STAR), University of Maryland School of Medicine, Baltimore, Maryland 21201, USA ${ }^{8}$ These authors contributed equally to this work.

'Corresponding author

E-mail frickk@uwm.edu

Article is online at http://www.learnmem.org/cgi/doi/10.1101/lm.026732.112.
Much recent attention has focused on the role of the mammalian target of rapamycin (mTOR) signaling pathway in regulating hippocampal memory consolidation (Ehninger et al. 2009; Richter and Klann 2009; Hoeffer and Klann 2010). mTOR is a $289-\mathrm{kD}$ serine/threonine protein kinase that regulates numerous cellular processes, including cell proliferation and survival, protein synthesis, and autophagy (Laplante and Sabatini 2012). mTOR complexes with two groups of proteins to affect different cellular processes. In the mTOR complex 1 (mTORC1), mTOR complexes with Raptor (regulatory associated protein of mTOR), PRAS40, and LST8. This mTORC1 complex regulates translation initiation by phosphorylating core components of the protein synthesis machinery, including p70 ribosomal S6 kinase (S6K) and eukaryotic initiation factor 4E-binding proteins (4E-BPs) (Hoeffer and Klann 2010). mTORC1 signaling is blocked by rapamycin, an inhibitor that prevents mTOR from complexing with other proteins and phosphorylating S6K and 4E-BP1 (Hoeffer and Klann 2010). In addition to protein synthesis, mTORC1 also regulates organismic longevity (Hoeffer and Klann 2010; Lamming et al. 2010). In the mTOR complex 2 (mTORC2), mTOR complexes with Rictor (rapamycin-insensitive companion of mTOR), Sin1, and LST8 to regulate proteins involved in cytoskeletal structure, signal transduction, and glucose homeostasis (Hoeffer and Klann 2010; Lamming et al. 2010). mTORC2 is thought to be insensitive to rapamycin (Hoeffer and Klann 2010), but work from cancer cells and genetically altered mice suggests this is not necessarily the case (Kelleher et al. 2004; Chen et al. 2010). mTOR signaling is activated in hippocampal dendrites in response to stimuli that induce long-term potentiation (LTP) and is necessary for the formation of stable hippocampal LTP (Cammalleri et al. 2003; Tsokas et al. 2005). Hippocampal 
learning also increases phosphorylation of mTOR and downstream substrates such as $\mathrm{S} 6 \mathrm{~K}$, presumably through the actions of mTORC1 (Parsons et al. 2006; Bekinschtein et al. 2007). The necessity of such activation for hippocampal memory consolidation has been demonstrated through the use of rapamycin. Hippocampal infusions of rapamycin prevent long-term consolidation of contextual fear, spatial, and object recognition memories (Dash et al. 2006; Parsons et al. 2006; Bekinschtein et al. 2007; Myskiw et al. 2008), suggesting a general involvement of mTOR in the primary types of memory regulated by the hippocampus.

mTOR is regulated by numerous upstream kinases, including extracellular signal-regulated kinase (ERK) and phosphatidylinositol 3-kinase (PI3K) (for reviews, see Richter and Klann 2009; Hoeffer and Klann 2010; Laplante and Sabatini 2012). In the canonical mTOR pathway, PI3K, which can be activated by G-protein-coupled receptors, receptor tyrosine kinases, and ion channels, phosphorylates Akt, which inhibits the tuberous sclerosis complex 2 (TSC2) (Tsokas et al. 2005). TSC2 inhibits the small GTPase Ras homologue enriched in brain (Rheb), which activates mTOR (Li et al. 2004). Therefore, activation of PI3K/Akt leads to activation of mTOR through disinhibition of Rheb. The PI3K/Akt pathway regulates hippocampal dendritic size and complexity (Kumar et al. 2005), and is critical for hippocampal LTP and the formation of object recognition and fear memories (Chen et al. 2005; Horwood et al. 2006; Cui et al. 2010). An essential role of PI3K in regulating mTOR signaling has been shown using the PI3K inhibitor LY294002, which decreases dendritic spine number, prevents the phosphorylation of Akt and $\mathrm{S} 6 \mathrm{~K}$, and reduces hippocampal mTOR phosphorylation after LTP induction and morphine treatment (Chen et al. 2005; Horwood et al. 2006; Cui et al. 2010). Like PI3K, ERK activation is critical for hippocampal LTP and several types of hippocampal memory, including object recognition (Atkins et al. 1998; Blum et al. 1999; Kelly et al. 2003). ERK can be activated by numerous mechanisms, including PI3K activation (Adams et al. 2000), and ERK activation can both directly and indirectly phosphorylate mTOR (Ser-2481) and S6K (Thr-421) (Kelleher et al. 2004; Pende et al. 2004; Tsokas et al. 2005; Winter et al. 2011). ERK promotes this mTORC1 signaling by inhibiting TSC2 (Winter et al. 2011) and activating S6K (Tsokas et al. 2005). Both ERK and mTOR must phosphorylate S6K for S6K to be optimally activated (Kumar et al. 2005), and ERK is necessary for activation of S6K in hippocampal dendrites (Tsokas et al. 2005). Importantly for memory, ERK-induced regulation of the mTOR pathway in the hippocampus is critical for dendritic morphogenesis (Kumar et al. 2005) and for the up-regulation of translational proteins during LTP (Tsokas et al. 2005). Interestingly, reciprocal interactions have been reported between ERK and PI3K in the control of mTOR-mediated translation (Tsokas et al. 2005; Winter et al. 2011), and data from hippocampal slices support the notion of mTOR as a point of convergence for PI3K and ERK in regulating dendritic spine morphology (Kumar et al. 2005). Therefore, neural modulators, like $\mathrm{E}_{2}$, that affect the PI3K and ERK pathways are likely to influence mTOR signaling.

In female rodents, a single systemic injection or direct dorsal hippocampal infusion of $\mathrm{E}_{2}$ immediately after training (i.e., posttraining) in an object recognition task significantly enhances object recognition memory consolidation (Luine et al. 2003; Walf et al. 2006, 2008; Fernandez et al. 2008; Lewis et al. 2008; Fan et al. 2010; Zhao et al. 2010, 2012). Using the ERK activation inhibitors U0126 and SL327, we recently demonstrated that activation of ERK in the dorsal hippocampus is necessary for $\mathrm{E}_{2}$ to enhance object recognition memory in young or middle-aged ovariectomized mice (Fernandez et al. 2008; Fan et al. 2010). In further studies with the PI3K inhibitor LY294002 in middle-aged female mice, we demonstrated that the beneficial effect of $\mathrm{E}_{2}$ on object recognition was also dependent on PI3K activation, as was the $\mathrm{E}_{2}$-induced phosphorylation of p42 ERK (Fan et al. 2010). Importantly, $\mathrm{E}_{2}$ was shown to activate PI3K prior to activating ERK, as illustrated by the fact that LY294002 prevented $\mathrm{E}_{2}$ from activating ERK, whereas U0126 had no effect on the ability of $\mathrm{E}_{2}$ to activate PI3K (Fan et al. 2010). Given that both PI3K and ERK are critically involved in mTOR signaling, mTOR activation may be necessary for $\mathrm{E}_{2}$ to enhance object recognition memory. This hypothesis is supported by recent evidence from hippocampal cell culture showing that $\mathrm{E}_{2}$ rapidly increases dendritic mRNA translation and phosphorylation of S6K and 4E-BP1 in an ERK-dependent manner (Sarkar et al. 2010). Therefore, the present study tested whether posttraining dorsal hippocampal infusion of the mTOR inhibitor rapamycin could prevent intracerebroventricularly infused $\mathrm{E}_{2}$ from enhancing object recognition memory consolidation in young ovariectomized mice. Because the role of PI3K in mediating $\mathrm{E}_{2}$ 's effects on object recognition has not yet been tested in young mice, separate groups of mice were treated with $\mathrm{E}_{2}$ plus LY294002 or U0126 (as a positive control). Finally, effects of $\mathrm{E}_{2}$, with or without rapamycin, LY294002, or U0126, on phosphorylation of mTOR, S6K, and 4E-BP1 in the dorsal hippocampus were measured to assess estrogenic regulation of mTOR signaling. The data provide the first evidence that dorsal hippocampal mTOR signaling is necessary for $\mathrm{E}_{2}$ to enhance object memory consolidation.

\section{Results}

\section{Estradiol-induced enhancement of object recognition is dependent on dorsal hippocampal PI3K, ERK, and $\mathrm{mTOR}$ activation in young female mice}

We previously demonstrated that a single bilateral post-training infusion of $5 \mu \mathrm{g} \mathrm{E} \mathrm{E}_{2}$ into the dorsal hippocampus enhances object recognition in young (3-mo-old) and middle-aged (17-moold) ovariectomized mice (Fernandez et al. 2008; Fan et al. 2010; Zhao et al. 2010, 2012). In middle-aged females, we found that the $E_{2}$-induced enhancement of object recognition was dependent on dorsal hippocampal ERK and PI3K activation (Fan et al. 2010), but in young females we have thus far only demonstrated the critical involvement of ERK (Fernandez et al. 2008; Lewis et al. 2008; Zhao et al. 2010). Therefore, in the present study we sought to determine whether PI3K is also necessary for the $\mathrm{E}_{2}$-induced enhancement of object recognition in young females using the PI3K inhibitor LY294002. To demonstrate that the effects of PI3K inhibition on $\mathrm{E}_{2}$-induced enhancement object recognition did not result from a general prevention of object memory formation by LY294002, we needed to identify a dose of LY294002 that did not interfere with object recognition. During training, mice explored two identical objects until they had accumulated $30 \mathrm{sec}$ exploring both objects. Immediately after training, young females received bilateral dorsal hippocampal infusions of vehicle $(n=7), 0.05 \mu \mathrm{g} /$ side LY294002 $(n=7)$, or $0.005 \mu \mathrm{g} /$ side LY294002 $(n=7)$. Twenty-four hours later, object recognition was tested by allowing the mice to accumulate $30 \mathrm{sec}$ exploring an object identical to those from training (i.e., familiar) and a novel object. We have previously demonstrated that vehicle-infused mice spend more time with the novel object than chance ( $15 \mathrm{sec}) 24 \mathrm{~h}$ after training, indicating intact memory for the familiar object (Gresack et al. 2007). As such, this 24-h delay between training and testing was optimal to test the potential memory-impairing effects of LY294002. Mice receiving 0.05 $\mu \mathrm{g} /$ side LY294002 did not spend more time than chance with the novel object $\left(t_{(6)}=0.69, P>0.05\right.$; Fig. 1A), indicating that this dose impaired object recognition, and suggesting that PI3K activation is necessary for 24 -h object recognition in young ovariectomized mice. In contrast, mice receiving vehicle or $0.005 \mu \mathrm{g} /$ side LY294002 spent significantly more time than chance with 


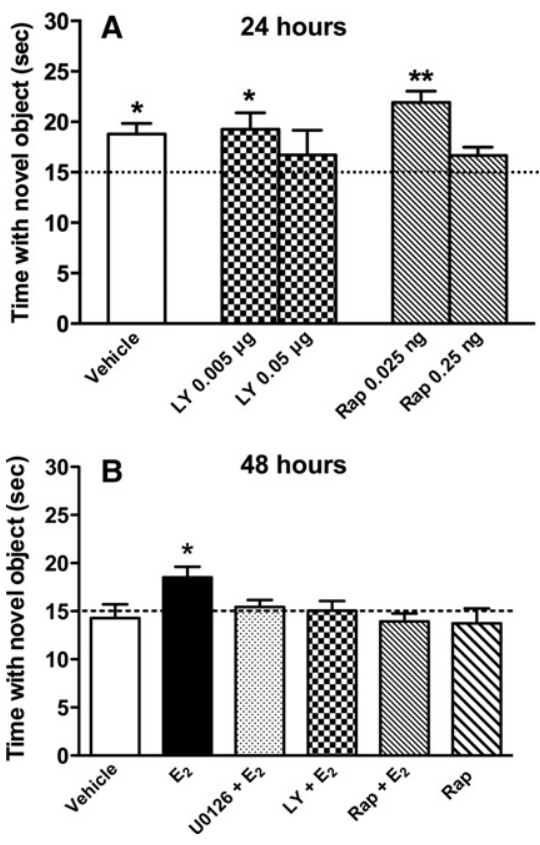

Figure 1. Object recognition in young ovariectomized mice. (A) Mice receiving bilateral dorsal hippocampal infusions of vehicle, LY294002 (LY) $(0.005 \mu \mathrm{g} / \mathrm{side})$, or Rapamycin (Rap) $(0.025 \mathrm{ng} / \mathrm{side})$ immediately after training spent significantly more time than chance (dashed line at $15 \mathrm{sec}$ ) with the novel object $24 \mathrm{~h}$ later, demonstrating that these inhibitor doses did not impair object recognition at this delay. However, mice receiving $0.05 \mu \mathrm{g} /$ side $\mathrm{LY}$ or $0.25 \mathrm{ng} /$ side rapamycin spent no more time than chance with the novel object, suggesting that higher doses reveal a critical involvement of PI3K and mTOR signaling in object recognition memory formation. (B) Mice receiving immediate post-training infusions of $E_{2}(5 \mu \mathrm{g} /$ side), but not vehicle, spent significantly more time with the novel object than chance $(15 \mathrm{sec}) 48 \mathrm{~h}$ after training, demonstrating that $E_{2}$ enhanced memory for the familiar object. Mice receiving $E_{2}$ plus U0126 $(0.5 \mu \mathrm{g} / \mathrm{side}), \mathrm{LY}(0.005 \mu \mathrm{g} / \mathrm{side})$, or Rap $(0.025 \mathrm{ng} / \mathrm{side})$ showed no preference for the novel object, suggesting that activation of ERK, PI3K, and mTOR are necessary for $\mathrm{E}_{2}$ to enhance object recognition. Infusion of Rap alone had no significant effect on object recognition. Each bar represents the mean ( \pm SEM) time spent with the novel object. $\left(^{*}\right) P<$ $0.05,\left({ }^{* *}\right) P<0.01$ relative to chance.

the novel object $\left(t_{(6)}=3.66, P<0.05\right.$ and $t_{(6)}=2.65, P<0.05$, respectively; Fig. 1A), suggesting that the $0.005 \mu \mathrm{g} /$ side dose does not impair object recognition. Because $0.005 \mu \mathrm{g} /$ side LY294002 did not prevent general object memory formation, this dose was used for all subsequent studies with $\mathrm{E}_{2}$.

We next used the mTOR inhibitor rapamycin to determine whether the $\mathrm{E}_{2}$-induced enhancement of object recognition was dependent on mTOR activation in the dorsal hippocampus. As with LY294002, we first determined that the effects of mTOR inhibition on $\mathrm{E}_{2}$-induced enhancement of object recognition did not result from general prevention of object memory formation by identifying a dose of rapamycin that did not interfere with 24 -h object recognition. Immediately after training, a new set of young ovariectomized females received bilateral dorsal hippocampal infusions of rapamycin at doses of $0.25 \mathrm{ng} / \mathrm{side}(n=5)$ or $0.025 \mathrm{ng} /$ side $(n=5)$. Twenty-four hours later, mice receiving vehicle or $0.025 \mathrm{ng} /$ side spent significantly more time with the novel object relative to chance $\left(t_{(6)}=3.66, P<0.05\right.$ and $t_{(4)}=6.12, P<0.01$, respectively), suggesting that the $0.025 \mathrm{ng} /$ side dose does not impair object recognition. Because $0.025 \mathrm{ng} /$ side rapamycin did not prevent general object memory formation, this dose was used for all subsequent studies with $\mathrm{E}_{2}$. Mice receiving $0.25 \mathrm{ng} /$ side rapamycin did not spend more time with the novel object than chance $\left(t_{(4)}=\right.$
2.00, $P>0.05$; Fig. 1A), indicating that this dose impaired object recognition. These data suggest that mTOR activation is necessary for object recognition in young ovariectomized mice.

Having identified doses of LY294002 and rapamycin that do not impair general memory formation, we then used these doses to determine whether PI3K and mTOR activation are necessary for $\mathrm{E}_{2}$ to enhance object recognition tested $48 \mathrm{~h}$ after training (a delay at which vehicle-infused mice forget the familiar object [Fernandez et al. 2008; Fan et al. 2010]). As a control, we also tested whether the ERK activation inhibitor U0126, at a dose $(0.5 \mu \mathrm{g} /$ side) that does not impair object recognition in young female mice, would also block the beneficial effects of $E_{2}$ on object recognition, as in our previous studies (Fernandez et al. 2008; Fan et al. 2010; Zhao et al. 2010). A new set of young ovariectomized females received a post-training bilateral infusion of vehicle $(50 \%$ DMSO in saline), U0126, LY294002, or rapamycin into the dorsal hippocampus, followed immediately by a dorsal third ventricle (intracerebroventricular, ICV) infusion of vehicle (2-hydroxypropyl- $\beta$-cyclodextrin, $\mathrm{HBC}$ ) or $10 \mu \mathrm{g} \mathrm{E}_{2}$ dissolved in saline. This infusion protocol allowed us to both infuse $\mathrm{E}_{2}$ into the brain and inhibit the effects of $E_{2}$ in the dorsal hippocampus without risking tissue damage in the dorsal hippocampus due to repeated infusions in this structure (Fernandez et al. 2008; Fan et al. 2010). Thus, immediately after object recognition training, each group received an ICV and dorsal hippocampal infusion, respectively, as follows: vehicle (50\% DMSO in saline followed by HBC in saline; $n=10), \mathrm{E}_{2}+$ DMSO vehicle $(n=8), \mathrm{E}_{2}+\mathrm{U} 0126$ (0.5 $\mu \mathrm{g} /$ side; $n=7), \mathrm{E}_{2}+\mathrm{LY294002}(0.005 \mu \mathrm{g} / \mathrm{side} ; n=6), \mathrm{E}_{2}+$ rapamycin $(0.025 \mathrm{ng} /$ side; $n=8)$, or HBC vehicle + rapamycin $(0.025 \mathrm{ng} /$ side; $n=7)$. Memory was tested $48 \mathrm{~h}$ later. Although vehicle-infused mice did not exhibit a preference for the novel object $\left(t_{(9)}=-0.25, P>0.05\right.$ relative to chance), $E_{2}$-infused mice spent significantly more time with the novel object relative to chance $\left(t_{(8)}=3.47, P=0.01\right.$; Fig. $\left.1 \mathrm{~B}\right)$, suggesting that $\mathrm{E}_{2}$ enhanced object recognition memory consolidation. This $\mathrm{E}_{2}$-induced memory enhancement was completely blocked by U0126 $\left(t_{(6)}=1.1\right.$, $P>0.05$ relative to chance), LY294002 $\left(t_{(6)}=0.42, P>0.05\right.$ relative to chance). and rapamycin $\left(t_{(7)}=-0.86, P>0.05\right.$ relative to chance; Fig. 1B). Consistent with its effects at the 24-h delay, rapamycin alone had no effect on object recognition memory consolidation $\left(t_{(6)}=-0.59, P>0.05\right.$ relative to chance). These data suggest that the beneficial effects of $E_{2}$ on object recognition are dependent on dorsal hippocampal activation of PI3K, ERK, and $\mathrm{mTOR}$ in young females.

\section{The estradiol-induced increase in dorsal hippocampal p42 ERK activation is dependent on PI3K and mTOR activation}

We previously showed that a single dorsal hippocampal infusion of $E_{2}$ increased ERK activation in the dorsal hippocampus after $5 \mathrm{~min}$ in young female mice and after $15 \mathrm{~min}$ in middle-aged female mice (Fernandez et al. 2008; Lewis et al. 2008; Fan et al. 2010; Zhao et al. 2010). In middle-aged females, this increase was dependent on PI3K activation (Fan et al. 2010). Therefore, we next determined whether U0126, LY294002, or rapamycin could block the $\mathrm{E}_{2}$-induced increase in $\mathrm{p} 42$ ERK phosphorylation. Mice received ICV and dorsal hippocampal infusions, respectively, as follows: HBC + DMSO vehicles $(n=5), \mathrm{E}_{2}+$ DMSO vehicle $(n=5), \mathrm{E}_{2}+\mathrm{U} 0126(n=5), \mathrm{E}_{2}+\mathrm{LY} 294002(n=5), \mathrm{E}_{2}+$ rapamycin $(n=5)$, or HBC vehicle + rapamycin $(n=5)$. The dorsal hippocampus was dissected bilaterally $5 \mathrm{~min}$ after dorsal hippocampal infusion. Phospho-p42 ERK levels differed significantly among the groups $\left(F_{(5,24)}=8.61, P<0.001\right)$. As in our previous studies (Fernandez et al. 2008; Lewis et al. 2008; Fan et al. 2010; Zhao et al. 2010, 2012), $\mathrm{E}_{2}$ significantly increased levels of 


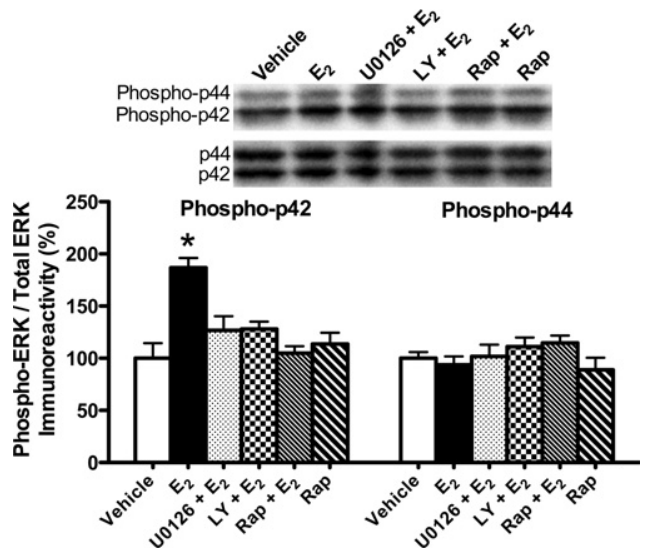

Figure 2. $p 42$ ERK and $p 44$ ERK phosphorylation in the dorsal hippocampus 5 min after drug infusion. Levels of phospho-p42 ERK ([*] $P<$ 0.001 ), but not of phospho-p44 ERK, were significantly increased in the dorsal hippocampus after $E_{2}$ infusion relative to vehicle. All three inhibitors (U0126, LY, and Rap) completely blocked this effect $(P<0.01$ relative to $E_{2}$ alone). Rap alone had no effect on phospho-p42 ERK levels. Phosphop44 ERK levels were not affected by any treatment. Phosphorylated p42 p44 protein levels were normalized to total p42/p44 protein levels. Each bar represents the mean $( \pm$ SEM) percent change from vehicle. (Insets) Representative Western blots show phosphorylated p42 ERK and p44 ERK protein levels.

phospho-p42 ERK, but not of phospho-p44 ERK, relative to vehicle $(P<0.001 ;$ Fig. 2$)$. The $\mathrm{E}_{2}$-induced increase in phospho-p42 ERK levels was blocked by all three inhibitors (all inhibitors $P<$ 0.01 relative to $\mathrm{E}_{2}$ group; Fig. 2). Rapamycin alone had no effect on phospho-p42 ERK levels ( $P>0.05$ relative to vehicle; Fig. 2 ), which is not surprising given that this dose had no detrimental effects on 24-h object recognition (Fig. 1A). Consistent with our previous studies (Fernandez et al. 2008; Fan et al. 2010), $\mathrm{E}_{2}$ and the inhibitors had no effect on phospho-p44 ERK levels $\left(F_{(5,24)}=\right.$ $1.17, P>0.05)$. Collectively, these data demonstrate that the $\mathrm{E}_{2}$-induced increase in p42 ERK phosphorylation is dependent on PI3K and mTOR activation, and suggest that LY294002 and rapamycin may prevent the memory-enhancing effects of $E_{2}$ by blocking dorsal hippocampal p42 ERK activation.

\section{mTOR activation at Ser-2448 and Ser-2481 was not altered by estradiol}

Phosphorylation of Ser-2448 and Ser-2481 on the C-terminal of mTOR is associated with increased mTOR activity (Hoeffer and Klann 2010). Ser-2448 can be phosphorylated by PI3K/Akt signaling and by S6K; Ser-2481 is an autophosphorylation site (Hoeffer and Klann 2010). Therefore, to determine if mTOR phosphorylation was altered by $\mathrm{E}_{2}$, and whether this effect could be blocked by inhibitors of ERK and PI3K activation, we examined phosphorylation of mTOR at Ser-2448 and Ser-2481 5 min after ICV and dorsal hippocampal infusion of $\mathrm{HBC}+\mathrm{DMSO}$ vehicles $(n=5), \mathrm{E}_{2}+$ DMSO vehicle $(n=5), \mathrm{E}_{2}+\mathrm{U} 0126(n=5), \mathrm{E}_{2}+\mathrm{LY} 294002(n=$ $5), \mathrm{E}_{2}+$ rapamycin $(n=5)$, or HBC vehicle + rapamycin $(n=5)$. Phospho-mTOR levels did not significantly differ among the groups for either Ser-2448 $\left(F_{(5,23)}=1.02, P>0.05\right.$; Fig. 3A) or Ser-2481 $\left(F_{(5,22)}=0.43, P>0.05\right.$; Fig. 3B $)$.

\section{The estradiol-induced increases in phosphorylated} S6K and 4E-BP1 were blocked by inhibitors of PI3K, ERK, and mTOR activation

We next examined the downstream effectors of mTOR, S6K, and $4 \mathrm{E}-\mathrm{BP} 1$. The phosphorylation of S6K is widely used as an indicator of mTOR activity (Dash et al. 2006; Bekinschtein et al. 2007; Slipczuk et al. 2009). S6K is phosphorylated by ERK at Thr-421 (Zhang et al. 2001; Lehman et al. 2003), so we examined levels of phospho-S6K (Thr-421) 5 min after infusion of vehicle, $E_{2}$, $\mathrm{E}_{2}+$ each inhibitor, or rapamycin. Dorsal hippocampi were collected $5 \mathrm{~min}$ after infusions of $\mathrm{HBC}+\mathrm{DMSO}$ vehicles $(n=5)$, $\mathrm{E}_{2}+$ DMSO vehicle $(n=5), \mathrm{E}_{2}+\mathrm{U} 0126(n=5), \mathrm{E}_{2}+\mathrm{LY} 294002$ $(n=5), \mathrm{E}_{2}+$ rapamycin $(n=5)$, or $\mathrm{HBC}$ vehicle + rapamycin $(n=5)$. Overall, there was a significant main effect of treatment $\left(F_{(5,23)}=4.48, P=0.005\right)$. $\mathrm{E}_{2}$ significantly increased phosphoS6K levels relative to vehicle $(P<0.01 ;$ Fig. $4 \mathrm{~A})$. This $\mathrm{E}_{2}$-induced increase in phospho-S6K levels was blocked by LY294002, U0126, and rapamycin (all inhibitors $P<0.05$ relative to vehicle and $\mathrm{E}_{2}$ groups; Fig. $4 \mathrm{~A}$ ), suggesting that activation of PI3K, ERK, and $\mathrm{mTOR}$ is necessary for $\mathrm{E}_{2}$ to increase $\mathrm{S} 6 \mathrm{~K}$ activation in the dorsal hippocampus.

4E-BP1 is another downstream indicator of mTOR activity in vivo (Hay and Sonenberg 2004). Under resting conditions, $4 \mathrm{E}-\mathrm{BP} 1$ is repressively bound to eIF4e, which prevents the initiation of translation. Phosphorylation of 4E-BP1 causes the dissociation of 4E-BP1 and eIF4e, which promotes translation (Hay and Sonenberg 2004). Therefore, we next examined levels of phospho-4E-BP1 (Thr 37/46) after ICV and dorsal hippocampal

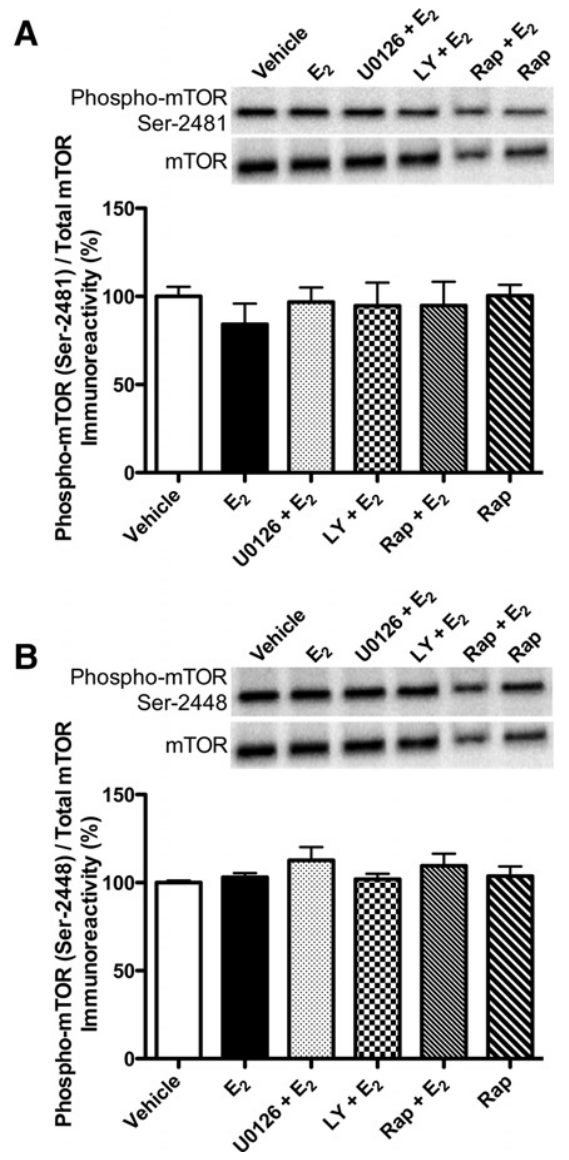

Figure 3. mTOR phosphorylation in the dorsal hippocampus $5 \mathrm{~min}$ after drug infusion. Levels of phospho-mTOR were not significantly altered by any treatment at the Ser-2481 (A) or Ser-2448 (B) sites. Phosphorylated mTOR protein levels were normalized to total mTOR protein levels. Each bar represents the mean $( \pm$ SEM) percent change from vehicle. (Insets) Representative Western blots show phosphorylated mTOR protein levels. 


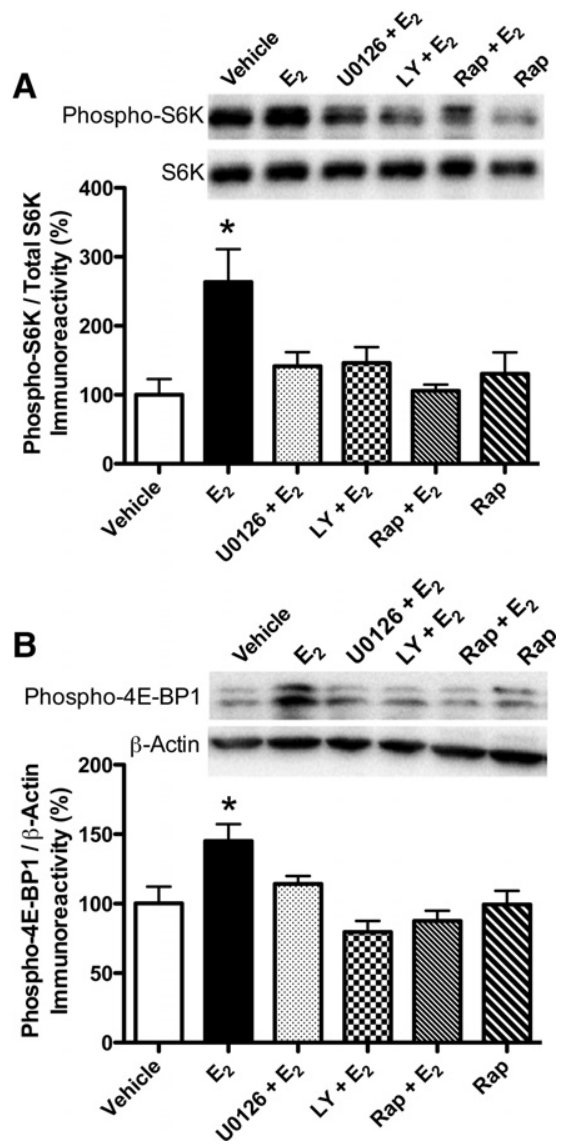

Figure 4. $\mathrm{S} 6 \mathrm{~K}$ and $4 \mathrm{E}-\mathrm{BP} 1$ phosphorylation in the dorsal hippocampus 5 min after drug infusion. (A) Levels of phospho-S6K (Thr-421) were increased by $E_{2}$ alone relative to vehicle $\left(\left[{ }^{*}\right] P<0.01\right)$. This effect was blocked by all three inhibitors $\left(P<0.05\right.$ relative to $E_{2}$ alone). Rap alone had no effect on phospho-S6K levels. (B) Levels of phospho-4E-BP1 (Thr-37/46) were increased by $E_{2}$ alone relative to vehicle $\left(\left[^{*}\right] P<\right.$ $0.01)$. This effect was blocked by all three inhibitors $(P<0.05$ relative to $E_{2}$ alone). Rap alone had no effect on phospho-4E-BP1 levels. Phosphorylated S6K and 4E-BP1 protein levels were normalized to total S6K and $\beta$-actin protein levels, respectively. Each bar represents the mean $( \pm$ SEM) percent change from vehicle. (Insets) Representative Western blots show phosphorylated S6K and 4E-BP1 protein levels.

infusion of HBC + DMSO vehicles $(n=5), \mathrm{E}_{2}+\mathrm{DMSO}$ vehicle $(n=5), \mathrm{E}_{2}+\mathrm{U} 0126(n=5), \mathrm{E}_{2}+\mathrm{LY} 294002(n=5), \mathrm{E}_{2}+$ rapamycin $(n=5)$, or HBC vehicle + rapamycin $(n=5)$. Dorsal hippocampi were collected bilaterally $5 \mathrm{~min}$ after dorsal hippocampal infusion. Activation of 4E-BP1 was significantly altered by treatment $\left(F_{(5,22)}=6.19, P<0.001\right)$. Specifically, phospho-4E-BP1 levels were significantly increased by $\mathrm{E}_{2}$ relative to vehicle $(P<0.01$; Fig. 4B), and this increase was blocked by all three inhibitors (all $P<0.05$ relative to vehicle and $\mathrm{E}_{2}$ groups; Fig. $4 \mathrm{~B}$ ). These data suggest that, like $\mathrm{S} 6 \mathrm{~K}$, the $\mathrm{E}_{2}$-induced activation of $4 \mathrm{E}-\mathrm{BP} 1$ in the dorsal hippocampus is dependent on activation of PI3K, ERK, and mTOR.

\section{Discussion}

The current study provides several novel findings with respect to the cell signaling mechanisms that mediate $\mathrm{E}_{2}$ 's effects on object recognition memory. These data show that ICV infusion of $\mathrm{E}_{2}$ rapidly increases dorsal hippocampal S6K (Thr-421) and 4E-BP1 (Thr 37/46) phosphorylation through an ERK-dependent mecha- nism. The study is also the first to demonstrate that dorsal hippocampal PI3K and mTOR signaling are necessary for $\mathrm{E}_{2}$ to enhance object recognition memory consolidation in young adult females. In combination with our current and previous findings that dorsal hippocampal ERK activation is also necessary for $\mathrm{E}_{2}$ to enhance object recognition in young adult females (Fernandez et al. 2008; Zhao et al. 2010), our data indicate that PI3K, ERK, and mTOR signaling all play critical roles in the estrogenic mediation of hippocampal memory formation.

The present study is the first to report that activation of mTOR signaling is necessary for $\mathrm{E}_{2}$ to enhance memory. This conclusion is supported by the fact that the beneficial effects of $E_{2}$ on object recognition were blocked by dorsal hippocampal infusion of the mTOR inhibitor rapamycin, and is consistent with literature demonstrating that mTOR signaling is required for several types of hippocampal memory, including object recognition (Dash et al. 2006; Parsons et al. 2006; Bekinschtein et al. 2007; Myskiw et al. 2008). However, it is important to note that the dose of rapamycin used here did not block object recognition or affect p42 ERK, mTOR, S6K, or 4E-BP1 on its own. Therefore, the observed effects of rapamycin in this study result from a specific interaction with the stimulatory actions of $\mathrm{E}_{2}$ on dorsal hippocampal function. The mTOR pathway has recently emerged as a primary regulator of hippocampal synaptic plasticity and memory (Hoeffer and Klann 2010). $\mathrm{E}_{2}$ can rapidly increase hippocampal spine synapse formation and mTOR signaling, and promotes new protein synthesis in hippocampal dendrites in an ERK-dependent manner (MacLusky et al. 2005; Mukai et al. 2010; Sarkar et al. 2010). Together with the present data, findings to date suggest that protein synthesis, particularly mTOR-mediated protein synthesis, underlies the memory-enhancing effects of $E_{2}$. Further, the fact that inhibition of PI3K and ERK signaling also prevented $\mathrm{E}_{2}$ from enhancing object recognition implicates the critical involvement of these well-known regulators of mTOR signaling (Winter et al. 2011).

The fact that the $\mathrm{E}_{2}$-induced enhancement in object recognition was dependent on ERK and PI3K activity is consistent with our previous data from young and middle-aged females (Fernandez et al. 2008; Fan et al. 2010; Zhao et al. 2010). Notably, young females appear less sensitive to the memory-impairing effects of the PI3K inhibitor LY294002 than middle-aged females, as indicated by the fact that $0.005 \mu \mathrm{g} /$ side LY294002 blocked 24-h object recognition in middle-aged females (Fan et al. 2010) but not in young females (present study). However, consistent with our previous data from middle-aged females, LY294002 prevented $E_{2}$ from increasing p42 ERK phosphorylation (Fan et al. 2010). As such, the data from both young and middle-aged females support the notion that the $E_{2}$-induced activation of p42 ERK in the dorsal hippocampus depends on initial PI3K activation.

In the present study, $\mathrm{E}_{2}$ alone significantly enhanced object recognition and increased phosphorylation of p42 ERK. The effects of $E_{2}$ on object recognition and p42 ERK phosphorylation are consistent with previous findings from our laboratory and others (Luine et al. 2003; Walf et al. 2006, 2008; Fernandez et al. 2008; Lewis et al. 2008; Fan et al. 2010; Zhao et al. 2010, 2012). Similar to p42 ERK, $\mathrm{E}_{2}$ also increased S6K (Thr-421) and 4E-BP1 (Thr 37/46) 5 min after infusion, but had no effect on mTOR phosphorylation (Ser-2481 and Ser-2448). The fact that $\mathrm{E}_{2}$ increased phospho-S6K and phospho-4E-BP1 levels is consistent with a recent cell culture study showing that $\mathrm{E}_{2}$ increases hippocampal dendritic mRNA translation and phosphorylation of S6K and 4E-BP1 (Sarkar et al. 2010). This finding is also supported by data that chronic $E_{2}$ attenuates ischemia-induced reductions of mTOR and S6K levels in the cerebral cortex of female rats (Koh et al. 2008), and reports that the related sex steroid hormones progesterone and testosterone can, 
respectively, increase phosphorylation of S6K in the dorsal hippocampus (Orr et al. 2012) and mTOR (Ser-2481) in myoblasts (Wu et al. 2010). It is interesting, however, that $\mathrm{E}_{2}$ did not affect mTOR phosphorylation at Ser-2481 or Ser-2448. Ser-2448 is phosphorylated by upstream PI3K signaling and by downstream S6K via negative feedback (Chiang and Abraham 2005). Thus, we expected $\mathrm{E}_{2}$ to increase phosphorylation at this site. Several possible explanations may account for the lack of effect at this site. S6K and/or 4E-BP1 may be phosphorylated directly by PI3K and ERK, thus bypassing mTOR entirely. We find this explanation unlikely given that rapamycin blocks $\mathrm{E}_{2}$ 's effects on object recognition and activation of S6K and 4E-BP1. However, mTOR could be involved without being significantly increased by $\mathrm{E}_{2}$ if the increased ERK signaling induced by $\mathrm{E}_{2}$ recruits more $\mathrm{S} 6 \mathrm{~K}$ and $4 \mathrm{E}-\mathrm{BP} 1$ for permissive phosphorylation by mTOR at downstream sites. Alternatively, the Ser-2448 site may be so rapidly phosphorylated that phospho-protein levels return to baseline by $5 \mathrm{~min}$ post-infusion. This would suggest that $\mathrm{E}_{2}$ rapidly and transiently activates mTOR. Interestingly, a significant increase in phosphoS6K without a change in phosphorylation at mTOR 2448 was recently observed in a study examining the role of local protein synthesis in THC-mediated memory impairment (Puighermanal et al. 2009), suggesting that our findings of downstream activation only are not unique. The Ser-2481 site on mTOR is an autophosphorylation site regulated by intrinsic mTOR activity (Peterson et al. 2000), but is not traditionally studied as an indicator of mTOR mediated local protein synthesis. Therefore, it is less surprising that we did not see an increase in phosphorylation at this site. Recently, three additional phosphorylation sites on mTOR have been identified (Ser-1261, Ser-2159, Thr-2164) (Acosta-Jaquez et al. 2009; Ekim et al. 2011) and phosphorylation of Ser-1261 has recently been implicated as the upstream factor responsible for 4E-BP1 and S6k phosphorylation (Acosta-Jaquez et al. 2009), suggesting other potential sites of $E_{2}$ modulation. These sites should be examined in future studies to better understand how $\mathrm{E}_{2}$ regulates mTOR phosphorylation.

The fact that rapamycin prevented the $\mathrm{E}_{2}$-induced increase in phospho-p42 ERK was unexpected, and may be mediated by one of the mTOR complexes, mTORC1 or mTORC2. mTORC1 is sensitive to rapamycin and is known to regulate protein synthesis in the hippocampus (Klann and Dever 2004; Tsokas et al. 2005; Hoeffer and Klann 2010). Data from cancer cells and genetically altered mice suggest that mTORC2 may also be sensitive to rapamycin (Kelleher et al. 2004; Chen et al. 2010). Particularly relevant for the present study, data from breast and prostate cancer cells illustrate that low concentrations of rapamycin activate ERK through mTORC1, whereas higher doses inhibit ERK phosphorylation via mTORC2 (Chen et al. 2010). These findings suggest that mTORC1 inhibits ERK and mTORC2 activates ERK. The mTORC1 data from cancer cells are consistent with previous reports from glioblastoma cells (Sunayama et al. 2010) and hippocampal neurons (Kelleher et al. 2004), suggesting that mTOR inhibits ERK phosphorylation. However, the demonstration that ERK in breast and prostate cancer cells can be activated through mTORC2 may help shed light on the current findings. Although it is difficult to extrapolate doses from non-neuronal cell culture to the intact brain, the cell culture data raise the possibility that $\mathrm{E}_{2}$ may increase ERK phosphorylation, in part, by stimulating mTORC2, and that rapamycin blocks this activation. Phosphorylation of Ser-2481 on mTOR also affects activity of mTORC2 (Soliman et al. 2010), and the recent demonstration that mTORC2 is sensitive to rapamycin (Lamming et al. 2010) lends some support to this hypothesis. Alternatively, rapamycin may fundamentally affect $\mathrm{E}_{2}$ signaling in the dorsal hippocampus in a way that alters $\mathrm{E}_{2}$ 's typical effects on ERK. Evidence for this possibility comes from a report that rapamycin in breast cancer cells blocks IGF-induced estrogen receptor $\alpha(\mathrm{ER} \alpha)$ phosphorylation and promoter binding in an mTORC1-dependent manner (Becker et al. 2011). These possibilities suggest at least two intriguing ways in which mTOR might influence the $\mathrm{E}_{2}$-induced activation of ERK. Clearly, these hypotheses will need to be tested in future studies to determine whether mTORC2 or rapamycininduced changes in $\mathrm{E}_{2}$ signaling contribute to the effects on ERK seen here after co-administration of $\mathrm{E}_{2}$ and rapamycin.

In conclusion, the present study demonstrates for the first time that the $E_{2}$-induced enhancement of object recognition memory consolidation in young females is dependent on PI3K and mTOR activation in the dorsal hippocampus. These data suggest that rapid protein synthesis in the dorsal hippocampus, possibly within dendritic spines, is necessary for $\mathrm{E}_{2}$ to enhance object recognition memory consolidation in young females. As such, these data provide important new insights into the molecular mechanisms underlying estrogenic modulation of object recognition memory consolidation.

\section{Materials and Methods}

\section{Subjects}

Eight- to 10-wk-old female C57BL/6 mice were obtained from Taconic (Germantown, New York, and Cambridge City, Indiana). Mice were housed four to five per cage until surgery. Mice were maintained on a 12-h light/dark cycle and had ad libitum access to food and water. All procedures followed the National Institutes of Health Guide for the Care and Use of Laboratory Animals and were approved by the University of Wisconsin-Milwaukee Institutional Animal Care and Use Committee and the Yale University Animal Care and Use Committee.

\section{Surgery}

Mice were ovariectomized and implanted with intracranial guide cannulae in the same surgical session, as described previously (Fernandez et al. 2008; Lewis et al. 2008; Fan et al. 2010). All mice were implanted with stainless-steel triple guide cannulae (Plastics One); two guides aimed bilaterally at the dorsal hippocampus and one guide aimed at the dorsal third ventricle (ICV). Mice were anesthetized with isoflurane gas (5\% for induction, $2 \%$ for maintenance). Using a stereotaxic apparatus (Kopf Instruments), guide cannulae (C232GC, 22 gauge; Plastics One) with inserted dummy cannulae (C232DC) were directed toward the dorsal hippocampus $(-1.7 \mathrm{~mm}$ posterior to bregma, $\pm 1.5 \mathrm{~mm}$ lateral to midline, $-2.3 \mathrm{~mm}$ [injection site] ventral to skull surface) and dorsal third ventricle $(-0.9 \mathrm{~mm}$ posterior to bregma, $\pm 0.0 \mathrm{~mm}$ from midline, $-2.8 \mathrm{~mm}$ [injection site] ventral to skull surface) (Paxinos and Franklin 2003). Each cannula was fixed to the skull with dental cement that also served to close the wound. Mice recovered for 5-7 d before testing or drug treatment.

\section{Drugs and infusions}

Cyclodextrin-encapsulated $\mathrm{E}_{2}$ (Sigma-Aldrich) was dissolved in physiological saline to a dose of $5.0 \mu \mathrm{g} / 0.5 \mu \mathrm{L}$. The $\mathrm{E}_{2}$ vehicle, 2-hydroxypropyl- $\beta$-cyclodextrin (HBC, Sigma-Aldrich), was dissolved in saline to the same concentration of cyclodextrin as in the cyclodextrin- $\mathrm{E}_{2}$ solution. Vehicle or $\mathrm{E}_{2}$ was infused into the dorsal third ventricle (intracerebroventricular, ICV) at a rate of $0.5 \mu \mathrm{L} / \mathrm{min}$ for $2 \mathrm{~min}$, resulting in a dose of $10 \mu \mathrm{g} \mathrm{E}$. This dose infused ICV in young ovariectomized mice facilitates object memory consolidation (Fernandez et al. 2008; Zhao et al. 2010). In the experiments described below in which $\mathrm{E}_{2}$ was infused ICV in conjunction with a dorsal hippocampal infusion of vehicle or an inhibitor, the ICV infusion was administered immediately after dorsal hippocampal infusion.

To demonstrate that $\mathrm{E}_{2}$-enhanced object recognition consolidation is dependent on dorsal hippocampal ERK activation, the 
MEK inhibitor 1,4-diamino-2,3-dicyano-1,4-bis(o-aminophenylmercapto)butadiene (U0126, Promega) was infused at a rate of $0.5 \mu \mathrm{L} / \mathrm{min}$ for $1 \mathrm{~min}$ per side of dorsal hippocampus. The concentration of U0126 was $0.5 \mu \mathrm{g} / 0.5 \mu \mathrm{L}$ in $50 \%$ dimethylsulfoxide (DMSO) in saline, resulting in a dose of $0.5 \mu \mathrm{g} /$ side of the hippocampus. In young ovariectomized mice, dorsal hippocampal infusion of this dose of U0126 does not block object recognition tested $24 \mathrm{~h}$ after training (Fernandez et al. 2008). The vehicle control for U0126 was 50\% DMSO in saline.

To demonstrate that $\mathrm{E}_{2}$-enhanced object recognition consolidation was dependent on dorsal hippocampal PI3K activation, the PI3K inhibitor LY294002 (Cell Signaling Technology) was dissolved in $100 \%$ DMSO to $3 \mu \mathrm{g} / \mu \mathrm{L}$ as a stock solution and then serially diluted in physiological saline for infusion of various doses. We first determined a dose of LY294002 that did not impair object recognition tested $24 \mathrm{~h}$ after training in young ovariectomized mice. We previously reported that post-training dorsal hippocampal infusions of $0.0005 \mu \mathrm{g} /$ side LY294002 did not block 24-h object recognition in middle-aged mice (Fan et al. 2010). Because our pilot work suggested that the hippocampus of young mice was less susceptible to the memory-impairing effects of LY294002, we infused doses of 0.05 and $0.005 \mu \mathrm{g} /$ side into the dorsal hippocampus of young females immediately after training and tested object recognition $24 \mathrm{~h}$ later. Both doses were infused at a rate of $0.5 \mu \mathrm{L} / \mathrm{min}$ and a volume of $0.5 \mu \mathrm{L} /$ side. Only a dose that did not impair 24-h object recognition was used in subsequent studies with $\mathrm{E}_{2}$. The vehicle control for LY294002 was $50 \%$ DMSO in saline.

To demonstrate that $\mathrm{E}_{2}$-enhanced object recognition consolidation was dependent on dorsal hippocampal mTOR activation, the mTOR inhibitor rapamycin (Sigma) was dissolved in 100\% DMSO to $1 \mu \mathrm{g} / \mu \mathrm{L}$ as a stock solution and then serially diluted in physiological saline for infusion of various doses. We first determined a dose of rapamycin that did not impair 24-h object recognition in young ovariectomized mice. Post-training dorsal hippocampal infusions of $0.9 \mathrm{ng} /$ side rapamycin impaired spatial memory in the Morris water maze $48 \mathrm{~h}$ after training (Dash et al. 2006). Therefore, we infused much lower doses $(0.25$ and $0.025 \mathrm{ng} /$ side) for our dose-response study. Rapamycin was infused at a rate of $0.5 \mu \mathrm{L} / \mathrm{min}$ and a volume of $0.5 \mu \mathrm{L} /$ side. Only a dose that did not impair 24-h object recognition was used in subsequent studies with $\mathrm{E}_{2}$. The vehicle control for rapamycin was $50 \%$ DMSO in saline.

Drug infusions were conducted as described previously (Fernandez et al. 2008; Fan et al. 2010; Zhao et al. 2010, 2012). During drug infusions, mice were gently restrained. Dummy cannulae were replaced with injection cannulae (C232I; 26 gauge, extending $0.8 \mathrm{~mm}$ beyond the $1.5 \mathrm{~mm}$ guide for dorsal hippocampus and $1.0 \mathrm{~mm}$ beyond for ICV infusions) attached to polyethylene tubing (PE50) connected to a 5- $\mu \mathrm{L}$ Hamilton syringe. All inhibitors (or vehicle) were infused bilaterally into the dorsal hippocampus, followed immediately by a single ICV infusion to deliver $\mathrm{E}_{2}$ or $\mathrm{HBC}$ vehicle into the dorsal third ventricle. Infusions were controlled by a microinfusion pump (KDS 100, KD Scientific). Infusion cannulae remained in place for $1 \mathrm{~min}$ after infusion to prevent diffusion back up the cannula track. For behavioral testing, all mice were infused immediately after object recognition training.

\section{Object recognition}

The object recognition task was conducted as described previously (Frick and Gresack 2003; Fernandez et al. 2008), and was used to assess nonspatial hippocampal memory (Clark et al. 2000; Baker and Kim 2002). The task consisted of habituation, training, and testing phases conducted on separate days. During habituation, mice were allowed to freely explore an empty white box $(60 \mathrm{~cm}$ $\mathrm{W} \times 60 \mathrm{~cm} \mathrm{~L} \times 47 \mathrm{~cm} \mathrm{H}$ ) for $5 \mathrm{~min} /$ day for $2 \mathrm{~d}$. No data were recorded. Twenty-four hours later, mice were rehabituated in the same box for $2 \mathrm{~min}$, and then placed in a holding cage while two identical objects were placed in the left and right corners ( $\sim 5 \mathrm{~cm}$ from the walls) of the box. Mice were then immediately returned to the box and allowed to freely investigate until they accumulated a total of $30 \mathrm{sec}$ exploring the objects. Exploration was recorded when the front paws or nose contacted either object. Mice were then immediately infused and returned to their home cage. After 24 or $48 \mathrm{~h}$, object recognition was tested, using the same procedure as in training except that a novel object was substituted for one of the familiar training objects. Novel object location was counterbalanced across mice. Time spent with each object was recorded using ANYmaze software (Stoelting). Mice inherently prefer to explore novel objects; thus, a preference for the novel object (more time than chance [15 sec] with the novel object) indicates intact memory for the familiar object. The use of 30 -sec total exploration time rather than a fixed trial duration minimizes confounding influences of group differences in activity. Young ovariectomized mice remember the familiar object after $24 \mathrm{~h}$, but not after $48 \mathrm{~h}$ (Gresack et al. 2007), allowing impairing effects of drugs to be observed using the 24-h delay and enhancing effects of drugs to be observed using the 48-h delay.

\section{Western blotting}

Mice received ICV and dorsal hippocampal infusions as described above and were then decapitated 5 min after ICV infusion. The dorsal hippocampus was immediately dissected bilaterally on ice and frozen at $-80^{\circ} \mathrm{C}$ until homogenized. Western blotting was conducted as described previously (Fernandez et al. 2008; Lewis et al. 2008; Fan et al. 2010). Briefly, all tissue samples were resuspended $1: 25 \mathrm{w} / \mathrm{v}$ in lysis buffer and homogenized with a probe sonicator (Branson Sonifier 250). Homogenates were electrophoresed on Tris- $\mathrm{HCl}$ gels and blotted to polyvinylidene fluoride (PVDF) membranes using the TransBlot Turbo system (BioRad). Western blots were blocked and incubated with primary antibodies (anti-phospho-p44/42 MAPK [1:2000], anti-phosphomTOR [Ser-2448 or Ser-2481] [1:1000], anti-phospho-p70S6K [Thr-421], and anti-phospho-4E-BP1 [Thr-37/46] [1:1000], Cell Signaling Technology) overnight. Blots were then incubated with the appropriate secondary antibody conjugated to horseradish peroxidase (Cell Signaling Technology) and developed using West Dura chemiluminescent substrate (Pierce Laboratories). Densitometry was conducted using Carestream Molecular Imaging software version 5.3.2 on the Carestream Gel Logic 6000 Pro (Carestream Healthcare). Blots were then stripped and re-probed with primary antibodies for anti-total-p44/42 MAPK (1:2000), anti-total-mTOR (1:1000), anti-total-S6K (1:1000), and anti- $\beta$-actin (1:100) (Cell Signaling Technology) for phosphoprotein normalization.

\section{Statistical analyses}

For object recognition data, separate one-sample $t$-tests were performed for each group to determine whether the time spent with the novel object differed from $15 \mathrm{sec}$. This analysis was used because time spent with the objects is not independent; time spent with one object reduces time spent with the other object (Gresack and Frick 2004, 2006). Western blotting data were analyzed using one-way analysis of variance followed by NewmanKeuls post hoc tests to compare between groups. Significance was determined at $P<0.05$.

\section{Acknowledgments}

This project was supported by a grant from the National Institute on Aging (AG022525) to K.M.F., an Ellison Medical Foundation/ AFAR Postdoctoral Fellowship to A.M.F., the University of Wisconsin-Milwaukee, and Yale University.

\section{References}

Acosta-Jaquez HA, Keller JA, Foster KG, Ekim B, Soliman GA, Feener EP, Ballif BA, Fingar DC. 2009. Site-specific mTOR phosphorylation promotes mTORC1-mediated signaling and cell growth. Mol Cell Biol 29: $4308-4324$. 
Adams JP, Roberson ED, English JD, Selcher JC, Sweatt JD. 2000. MAPK regulation of gene expression in the central nervous system. Acta Neurobiol Exp 60: 377-394.

Akama KT, McEwen BS. 2003. Estrogen stimulates postsynaptic density-95 rapid protein synthesis via the Akt/protein kinase B pathway. J Neurosci 23: 2333-2339.

Atkins CM, Selcher JC, Petraitis JJ, Trzaskos JM, Sweatt JD. 1998. The MAPK cascade is required for mammalian associative learning. Nat Neurosci 1: 602-609.

Baker KB, Kim JJ. 2002. Effects of stress and hippocampal NMDA receptor antagonism on recognition memory in rats. Learn Mem 9: 58-65.

Becker MA, Ibrahim YH, Cui X, Lee AV, Yee D. 2011. The IGF pathway regulates ER $\alpha$ through a S6K1-dependent mechanism in breast cancer cells. Mol Endocrinol 25: 516-528.

Bekinschtein P, Katche C, Slipczuk LN, Igaz LM, Cammarota M, Izquierdo I, Medina JH. 2007. mTOR signaling in the hippocampus is necessary for memory formation. Neurobiol Learn Mem 87: 303-307.

Blum S, Moore AN, Adams F, Dash PK. 1999. A mitogen-activated protein kinase cascade in the CA1/CA2 subfield of the dorsal hippocampus is essential for long-term spatial memory. J Neurosci 19: 3535-3544.

Brake WG, Alves SE, Dunlop JC, Lee SJ, Bulloch K, Allen PB, Greengard P, McEwen BS. 2001. Novel target sites for estrogen action in the dorsal hippocampus: An examination of synaptic proteins. Endocrinology 142: $1284-1289$.

Cammalleri M, Lütjens R, Berton F, King AR, Simpson C, Francesconi W, Sanna PP. 2003. Time-restricted role for dendritic activation of the mTOR-p70S6K pathway in the induction of late-phase long-term potentiation in the CA1. Proc Natl Acad Sci 100: 14368-14373.

Chen X, Garelick MG, Wang H, Lil V, Athos J, Storm DR. 2005. PI3 kinase signaling is required for retrieval and extinction of contextual memory. Nat Neurosci 8: 925-931.

Chen XG, Liu F, Song XF, Wang ZH, Dong ZQ, Hu ZQ Lan RZ, Guan W, Zhou TG, Xu XM, et al. 2010. Rapamycin regulates Akt and ERK phosphorylation through mTORC1 and mTORC2 signaling pathways. Mol Carcinog 49: 603-610.

Chiang GG, Abraham RT. 2005. Phosphorylation of mammalian target of rapamycin (mTOR) at Ser-2448 is mediated by p70S6 kinase. J Biol Chem 280: $25485-25490$.

Choi J, Romeo R, Brake W, Bethea C, Rosenwaks Z, McEwen B. 2003. Estradiol increases pre- and post-synaptic proteins in the CA1 region of the hippocampus in female rhesus macaques (Macaca mulatta). Endocrinology 144: 4734-4738.

Clark RE, Zola SM, Squire LR. 2000. Impaired recognition memory in rats after damage to the hippocampus. J Neurosci 20: 8853-8860.

Cui Y, Zhang XQ, Cui Y, Xin WJ, Jing J, Liu XG. 2010. Activation of phosphatidylinositol 3-kinase/Akt-mammalian target of Rapamycin signaling pathway in the hippocampus is essential for the acquisition of morphine-induced place preference in rats. Neuroscience 171: 134-143.

Dash PK, Orsi SA, Moore AN. 2006. Spatial memory formation and memory-enhancing effect of glucose involves activation of the tuberous sclerosis complex-Mammalian target of rapamycin pathway. J Neurosci 26: 8048-8056.

Ehninger D, de Vries PJ, Silva AJ. 2009. From mTOR to cognition: Molecular and cellular mechanisms of cognitive impairments in tuberous sclerosis. J Intellect Disabil Res 53: 838-851.

Ekim B, Magnuson B, Acosta-Jaquez HA, Keller JA, Feener EP, Fingar DC 2011. mTOR kinase domain phosphorylation promotes mTORC1 signaling, cell growth, and cell cycle progression. Mol Cell Biol 31: $2787-2801$.

Fan L, Zhao Z, Orr PT, Chambers CH, Lewis MC, Frick KM. 2010. Estradiolinduced object memory consolidation in middle-aged female mice requires dorsal hippocampal extracellular signal-regulated kinase and phosphatidylinositol 3-kinase activation. J Neurosci 30: 4390-4400.

Fernandez SM, Lewis MC, Pechenino AS, Harburger LL, Orr PT, Gresack JE Schafe GE, Frick KM. 2008. Estradiol-induced enhancement of object memory consolidation involves hippocampal ERK activation and membrane-bound estrogen receptors. J Neurosci 28: 8660-8667.

Frick KM, Gresack JE. 2003. Sex differences in the behavioral response to spatial and object novelty in adult C57BL/6 mice. Behav Neurosci 117: 1283-1291.

Frick KM, Fernandez SM, Bulinski SC. 2002. Estrogen replacement improves spatial reference memory and increases hippocampal synaptophysin in aged female mice. Neuroscience 115: 547-558.

Frick KM, Fernandez SM, Bennett JC, Prange-Kiel J, MacLusky NJ, Leranth C. 2004. Behavioral training interferes with the ability of gonadal hormones to increase CA1 spine synapse density in ovariectomized female rats. Eur J Neurosci 19: 3026-3032.

Gresack JE, Frick KM. 2004. Environmental enrichment reduces the mnemonic and neural benefits of estrogen. Neuroscience 128: 459-471.

Gresack JE, Frick KM. 2006. Post-training estrogen enhances spatial and object memory consolidation in female mice. Pharmacol Biochem Behav 84: $112-119$.
Gresack JE, Kerr KM, Frick KM. 2007. Life-long environmental enrichment differentially affects the mnemonic response to estrogen in young, middle-aged, and aged female mice. Neurobiol Learn Mem 88: 393-408.

Hao J, Janssen WG, Tang Y, Roberts JA, McKay H, Lasley B, Allen PB, Greengard P, Rapp PR, Kordower JH, et al. 2003. Estrogen increases the number of spinophilin-immunoreactive spines in the hippocampus of young and aged female rhesus monkeys. J Comp Neurol 465: $540-550$.

Hay N, Sonenberg N. 2004. Upstream and downstream of mTOR. Genes Dev 18: $1926-1945$.

Hoeffer CA, Klann E. 2010. mTOR signaling: At the crossroads of plasticity, memory and disease. Trends Neurosci 33: 67-75.

Horwood JM, Dufour F, Laroche S, Davis S. 2006. Signalling mechanisms mediated by the phosphoinositide 3-kinase/Akt cascade in synaptic plasticity and memory in the rat. Eur J Neurosci 23: 3375-3384.

Kelleher RJ, Govindarajan A, Jung HY, Kang H, Tonegawa S. 2004. Translational control by MAPK signaling in long-term synaptic plasticity and memory. Cell 116: 467-479.

Kelly A, Laroche S, Davis S. 2003. Activation of mitogen-activated protein kinase/extracellular signal-regulated kinase in hippocampal circuitry is required for consolidation and reconsolidation of recognition memory. I Neurosci 12: $5354-5360$

Klann E, Dever TE. 2004. Biochemical mechanisms for translational regulation in synaptic plasticity. Nat Rev Neurosci 5: 931-942.

Klann E, Sweatt JD. 2008. Altered protein synthesis is a trigger for long-term memory formation. Neurobiol Learn Mem 89: 247-259.

Koh PO, Cho JH, Won CK, Lee HJ, Sung JH, Kim MO. 2008. Estradiol attenuates the focal cerebral ischemic injury through mTOR/p70S6 kinase signaling pathway. Neurosci Lett 436: 62-66.

Kumar V, Zhang MX, Swank MW, Kunz J, Wu GY. 2005. Regulation of dendritic morphogenesis by Ras-PI3K-Akt-mTOR and Ras-MAPK signaling pathways. J Neurosci 25: $11288-11299$.

Lamming DW, Ye L, Katajisto P, Goncalves MD, Saitoh M, Stevens DM, Davis JG, Salmon AB, Richardson A, Ahima RS, et al. 2010. Rapamycin-induced insulin resistance is mediated by mTORC2 loss and uncoupled from longevity. Science 335: 1638-1643.

Laplante M, Sabatini DM. 2012. mTOR signaling in growth control and disease. Cell 149: 274-293.

Lehman JA, Calvo V, Gomez-Cambronero J. 2003. Mechanism of ribosomal p70S6 kinase activation by granulocyte macrophage colony-stimulating factor in neutrophils: Cooperation of a MEK-related, THR421/SER424 kinase and a rapamycin-sensitive, m-TOR-related THR389 kinase. I Biol Chem 278: 28130-28138.

Lewis MC, Kerr KM, Orr PT, Frick KM. 2008. Estradiol-induced enhancement of object memory consolidation involves NMDA receptors and protein kinase $\mathrm{A}$ in the dorsal hippocampus of female C57BL/6 mice. Behav Neurosci 122: 716-721.

Li Y, Corradetti MN, Inoki K, Guan KL. 2004. TSC2: Filling the GAP in the mTOR signaling pathway. Trends Biochem Sci 29: 32-38.

Luine VN, Jacome LF, MacLusky NJ. 2003. Rapid enhancement of visual and place memory by estrogens in rats. Endocrinology 144: 2836-2844.

MacLusky NJ, Luine VN, Hajszan T, Leranth C. 2005. The $17 \alpha$ and $17 \beta$ isomers of estradiol both induce rapid spine synapse formation in the CA1 hippocampal subfield of ovariectomized female rats. Endocrinology 146: $287-293$.

Mukai H, Kimoto T, Hojo Y, Kawato S, Murakami G, Higo S, Hatanaka Y, Ogiue-Ikeda M. 2010. Modulation of synaptic plasticity by brain estrogen in the hippocampus. Biochim Biophys Acta Gen Subj 1800: $1030-1044$.

Myskiw JC, Rossato JI, Bevilaqua LR, Medina JH, Izquierdo I, Cammarota M. 2008. On the participation of mTOR in recognition memory. Neurobiol Learn Mem 89: 338-351.

Orr PT, Rubin AJ, Fan L, Kent BA, Frick KM. 2012. The progesterone-induced enhancement of object recognition memory consolidation involves activation of the extracellular signal-regulated kinase (ERK) and mammalian target of rapamycin (mTOR) pathways in the dorsal hippocampus. Horm Behav 61: 487-495.

Parsons RG, Gafford GM, Helmstetter FJ. 2006. Translational control via the mammalian target of rapamycin pathway is critical for the formation and stability of long-term fear memory in amygdala neurons. J Neurosci 26: 12977-12983.

Paxinos G, Franklin KBJ. 2003. The mouse brain in stereotaxic coordinates, 2nd ed. Academic Press, San Diego, CA.

Pende M, Um SH, Mieulet V, Sticker M, Goss VL, Mestan J, Mueller M, Fumagalli S, Kozma SC, Thomas G. 2004. S6K1 (-/-)/S6K2(-/-) mice exhibit perinatal lethality and rapamycin-sensitive $5^{\prime}$-terminal oligopyrimidine mRNA translation and reveal a mitogen-activated protein kinase-dependent S6 kinase pathway. Mol Cell Biol 24: $3112-3124$

Peterson RT, Beal PA, Comb MJ, Schreiber SL. 2000. FKBP12-rapamycinassociated protein (FRAP) autophosphorylates at serine 2481 
under translationally repressive conditions. J Biol Chem 275: 7416-7423.

Puighermanal E, Marsicano G, Busquets-Garcia A, Lutz B, Maldonado R, Ozaita A. 2009. Cannabinoid modulation of hippocampal longterm memory is mediated by mTOR signaling. Nat Neurosci 12: $1152-1158$.

Richter JD, Klann E. 2009. Making synaptic plasticity and memory last: Mechanisms of translational regulation. Genes Dev 23: 1-11.

Sarkar SN, Smith LT, Logan SM, Simpkins JW. 2010. Estrogen-induced activation of extracellular signal-regulated kinase signaling triggers dendritic resident mRNA translation. Neuroscience 170: 1080-1085.

Slipczuk L, Bekinschtein P, Katche C, Cammarota M, Izquierdo I, Medina JH. 2009. BDNF activates mTOR to regulate GluR1 expression required for memory formation. PLoS One 4: e6007.

Soliman GA, Acosta-Jaquez HA, Dunlop EA, Ekim B, Maj NE, Tee AR, Fingar DC. 2010. mTOR Ser-2481 autophosphorylation monitors mTORC-specific catalytic activity and clarifies rapamycin mechanism of action. I Biol Chem 285: 7866-7879.

Spencer JL, Waters EM, Milner TA, McEwen BS. 2008. Estrous cycle regulates activation of hippocampal Akt, LIM kinase, and neurotrophin receptors in C57BL/6 mice. Neuroscience 155: 1106-1119.

Sunayama J, Matsuda K, Sato A, Tachibana K, Suzuki K, Narita Y, Shibui S, Sakurada K, Kayama T, Tomiyama A, et al. 2010. Crosstalk between the $\mathrm{PI} 3 \mathrm{~K} / \mathrm{mTOR}$ and MEK/ERK pathways involved in the maintenance of self-renewal and tumorigenicity of glioblastoma stem-like cells. Stem Cells 28: 1930-1939.

Tsokas P, Grace EA, Chan P, Ma T, Sealfon SC, Iyengar R, Landau EM, Blitzer RD. 2005. Local protein synthesis mediates a rapid increase in dendritic elongation factor $1 \mathrm{~A}$ after induction of late long-term potentiation. J Neurosci 25: 5833-5843.

Walf AA, Rhodes ME, Frye CA. 2006. Ovarian steroids enhance object recognition in naturally cycling and ovariectomized, hormone-primed rats. Neurobiol Learn Mem 86: 35-46.
Walf AA, Koonce CJ, Frye CA. 2008. Estradiol or diarylpropionitrile administration to wild type, but not estrogen receptor $\beta$ knockout, mice enhances performance in the object recognition and object placement tasks. Neurobiol Learn Mem 89: 513-521.

Waters EM, Mitterling K, Spencer JL, Mazid S, McEwen BS, Milner TA. 2009. Estrogen receptor $\alpha$ and $\beta$ specific agonists regulate expression of synaptic proteins in rat hippocampus. Brain Res 1290: $1-11$.

Winter JN, Jefferson LS, Kimball SR. 2011. ERK and Akt signaling pathways function through parallel mechanisms to promote mTORC1 signaling. Am J Physiol Cell Physiol 300: C1172-C1180.

Woolley CS, McEwen BS. 1992. Estradiol mediates fluctuation in hippocampal synapse density during the estrous cycle in the adult rat. J Neurosci 12: 2549-2554.

Woolley CS, McEwen BS. 1993. Roles of estradiol and progesterone in regulation of hippocampal dendritic spine density during the estrous cycle in the rat. J Comp Neurol 336: 293-306.

Wu Y, Bauman WA, Blitzer RD, Cardozo C. 2010. Testosterone-induced hypertrophy of L6 myoblasts is dependent upon ERK and mTOR. Biochem Biophys Res Commun 400: 679-683.

Zhang Y, Dong Z, Nomura M, Zhong S, Chen N, Bode AM, Dong Z. 2001. Signal transduction pathways involved in phosphorylation and activation of p70S6K following exposure to UVA irradiation. J Biol Chem 276: 20913-20923.

Zhao Z, Fan L, Frick KM. 2010. Epigenetic alterations regulate the estradiol-induced enhancement of memory consolidation. Proc Natl Acad Sci 107: 5605-5610.

Zhao Z, Fan L, Fortress AM, Boulware MI, Frick KM. 2012. Hippocampal histone acetylation regulates object recognition and the estradiolinduced enhancement of object recognition. J Neurosci 32: 2344-2351.

Received April 18, 2012; accepted in revised form January 7, 2013. 


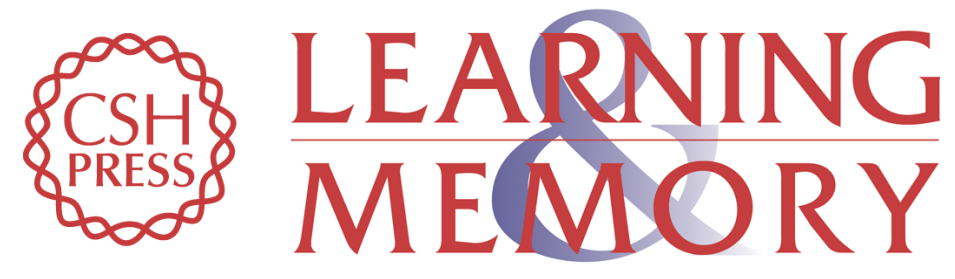

Estradiol-induced object recognition memory consolidation is dependent on activation of mTOR signaling in the dorsal hippocampus

Ashley M. Fortress, Lu Fan, Patrick T. Orr, et al.

Learn. Mem. 2013, 20:

Access the most recent version at doi:10.1101/lm.026732.112

References This article cites 68 articles, 24 of which can be accessed free at: http://learnmem.cshlp.org/content/20/3/147.full.html\#ref-list-1

License

Email Alerting Receive free email alerts when new articles cite this article - sign up in the box at the Service top right corner of the article or click here. 